\title{
Determinant Factors in the Effective Leadership of Secondary Schools: The Diminishing Trust Culture by Educators
}

\author{
Kaziba Abdul Mpaata ${ }^{1 *} \quad$ Umar Kakumba ${ }^{2}$ \\ 1. Faculty of Management Studies, Islamic University in Uganda, P.O. Box 2555, Mbale - Uganda \\ 2. College of Business and Management Sciences, Makerere University, Kampala - Uganda.
}

\begin{abstract}
The purpose of this paper is to explore the determinant factors in the effective leadership of secondary schools in Uganda. Factor Analysis was employed to appropriately identify variables for inclusion in subsequent analytical procedures. The use of an eigenvalue cut-off point of 1.0, as suggested by Kaiser, resulted in four factors which were then rotated using varimax rotation before the use of correlation and regression analyses to determine their significance. Factor analysis results revealed that there are four significant factors that determine effective leadership of secondary schools in Uganda. Further subsequent analysis then indicated that only three of the factors significantly determine effective leadership in schools which are; (i) the head teacher's ability to acquire instructional materials $[\beta=.246, \mathrm{t}=2.902, \mathrm{p}<0.004]$; (ii) their ability to supervise and manage the school $[\beta$ $=.175, \mathrm{t}=2.111, \mathrm{p}<0.037]$; and (iii) their influence over teaching and student assessment $[\beta=.544, \mathrm{t}=8.872, \mathrm{p}$ $<0.0001]$. The study documents the factors that have been empirically identified as key to the effective leadership of secondary schools in Uganda and therefore closes the gap on what should practically be done by stakeholders and especially educators to effectively lead schools and produce results.
\end{abstract}

Keywords: Leadership Effectiveness, Trust Culture, Trust Gap, Teaching

DOI: $10.7176 / \mathrm{JEP} / 11-33-10$

Publication date: November $30^{\text {th }} 2020$

\section{Introduction}

The present increasing demand by the Ministry of education for improved, balanced or excellent school performance from all districts in Uganda has definitely created a strong desire and impetus for effective school leaders. While current statistics indicate an increasing trend in the number of schools in the country, it is undisputable that there is also an equally growing need for competent head teachers at all levels (IGG Report, 2014). According to the Ministry of Education National Headcount Exercise report (2015), there were 1,155 Universal Secondary Education (USE), 791 government secondary schools and 364 private secondary schools by the year 2007. It is further observed that at present, this figure has more than doubled yet the available head teachers do not match with this growing trend. Consequently, as the proliferation of secondary schools increase, the country is expected to face a peculiarly consistent demand for head teachers who are able to not only supervise performance by initiating structure but also provide the necessary consideration and attention to the wellbeing of staff so as to stimulate the zeal, enthusiasm and trust required in the school setting. Despite the student numbers that increase from year to year, school leadership proficiency is increasingly diminishing in both technical and financial terms thereby widening the trust gap among the different actors in the education sector. The study by Anthony and Schneider (2003) document that teachers consider trust more important now than ever and this trust is based on the developed interpersonal dependency initiated by the head teacher. Effective school leaders not only demonstrate that they are paragons of efficiency and elegance per se but mentors who engage in trust building activities that enable the school to flourish and motivate stakeholders to get up to the task of preparing students to outwit and thwart all academic roadblocks in a subtlest of different ways.

The study here was motivated by the increasing poor performance of schools in Eastern Uganda with the exception of just a few. This view is supported by Ampurire (2018) who reported that the 2017 Uganda Certificate of Education (UCE) examinations results showed a higher failure rate of students in the Eastern region of Uganda. The conclusion was based on results from UNEB that pointed to a pattern of the steady trend that showed Eastern Uganda's poor performance at all levels of education compared to other regions. It is therefore urged here that effective leadership is a function of the head teacher's abilities, characteristics and behaviors that influence the functioning of the school. In other words, the head teacher's intellectual and task-relevant abilities in the motivation of staff play a significant role in the effective school leadership (Fleenor and Bryant, 2002). The study by Nigel et al. (2003) also support the analysis that effective school leaders are those with ability to exploit the diverse qualities of others thereby empowering them to practice management within the school. According to Duignan (2006), leadership effectiveness is hindered by a number of challenges such as providing a value-driven vision, managing staff relationships and effectively communicating with each group or department to prepare for continuous improvement and avoid poor performance. This study therefore set out to examine factors determining effective leadership using selected secondary schools in the Eastern region of Uganda.

The study is important because according to Laila (2015), the leader of a school is a principal who directs, 
administers and manages human and material educational resources in the school. Earlier studies such as that of MacBreath and Mortimore (2001) also indicated that effective educational leaders are preoccupied with improving educational achievements by ensuring quality of both the human and material resources in the delivery process. An effective leader is therefore the basis for institutional development which is in itself a source of competitive advantage. According to Block and Manning (2007), the essential roles of effective leaders include developing a vision and the strategies necessary to achieve not only the vision but to build an academic environment necessary for school growth, excellence and survival. In Uganda just like elsewhere in the educational sector, head teachers are therefore expected to come from among those individuals who are not only masters of their subjects but of their emotions and spend considerable time to build teams that appear civilized, descent, and fair in interaction with the different stakeholders. Conversely, the poor undesirable ones demonstrate greed, envy, lust, hatred and are only skillful at indirect manipulation.

According to Mpaata (2007), in the academic setting, one is categorized as a leader when is armed with one or more of the following realms as applied to leadership in table 1 below.

\begin{tabular}{|c|c|c|}
\hline No. & Realm & Meaning \\
\hline 1. & Time & To exist before \\
\hline 2. & Place & To arrive at before \\
\hline 3. & Route & To find the way before \\
\hline 4. & Skills & To have more skills \\
\hline 5. & Knowledge & To have more information \\
\hline 6. & Ability & To have more ability \\
\hline 7. & Power & To have more influence \\
\hline 8. & Experience & To have more history \\
\hline 9. & Learning & To have more learning \\
\hline 10. & Technology & To have a better way \\
\hline 11. & Paradigm & To have a better map or $\mathrm{m}$ \\
\hline
\end{tabular}

Leadership metaphor
Predecessor
Pioneer
Trailblazer
Expert
Authority
Master
Superior
Senior
Scholar
Inventor
Innovator

\section{Literature review}

Studies on effective leadership behavior are not new (Yukl, 2006), ever since they gained prominence in the 1950s following a series of studies by Ohio University that used factor analysis to identify two broad categories termed as; (1) consideration where the leader has concern for people and interpersonal relationships; and (2) initiating structure in which such a leader demonstrates concern for accomplishing tasks that are in line with the goals of the institution. This was followed by the Michigan leadership studies (Yukl, 2006), that subsequently identified three types of behaviors that distinguish between effective and ineffective leaders which include; (1) task oriented behavior that only focuses on task oriented functions such as planning and work scheduling; (2) relations-oriented behavior in which the leader concentrates on showing trust and confidence to subordinates; and (3) participative leadership where the leader uses more group or team supervision instead of supervising each and every individual alone.

Recently, Mpaata and Mpaata (2019) observed that the school head should be able to lobby government for the needed resources and also provide a conducive learning environment. In another research study, Mpaata and Mpaata (2018) concluded that the availability of effective leadership is critical to the implementation of the educational policies in Uganda. To support this view, the study by the Wallace Foundation (2012) identified various practices central to effective school leadership that among others include; (1) nurturing trust; (2) enabling teachers to teach at their best and students to learn at their utmost; and (3) managing people, data and records.

The finding of Olatunji, et al. (2011) documented that the attainment of educational goals is a function of the collective interplay of the internal and external forces to the school. The study advised effective school leader to diligently influence such forces to achieve the specified goals of the school. While analyzing the supervisory role of head teachers, Mpaata, et al. (2017) concluded that a school head is a planner and a manager of the educational process who is expected to have a super vision so as to effectively guide, communicate and play the leadership role both within and outside the school.

\subsection{The Trust Gap in the School Setting}

The notion that educators need to practice and utilize trust in the effect of management of schools is not debatable. Several studies such as that of Van Maele and Van Houtte (2009) document that trust is not only related to the effective functioning of the school but also it has a significant influence on the student performance and the teachers' sense of efficacy and job satisfaction. Thus, school leaders like managers of any other organization need to take stock and ensure that the trust gap is effectively closed as much as possible. Moreover, the study by Tschannen-Moran (2014) found that trust in the educational setting is pivotal in eliciting performance from the different school actors. 
Recent studies such as that of Lapton (2017) also document that the foundation of a trusting culture is the leader who is expected to build relationships, reward them and act with fairness. The details of this analysis are summarized in the Figure 1.

Figure 1. Foundations of a Trusting Culture

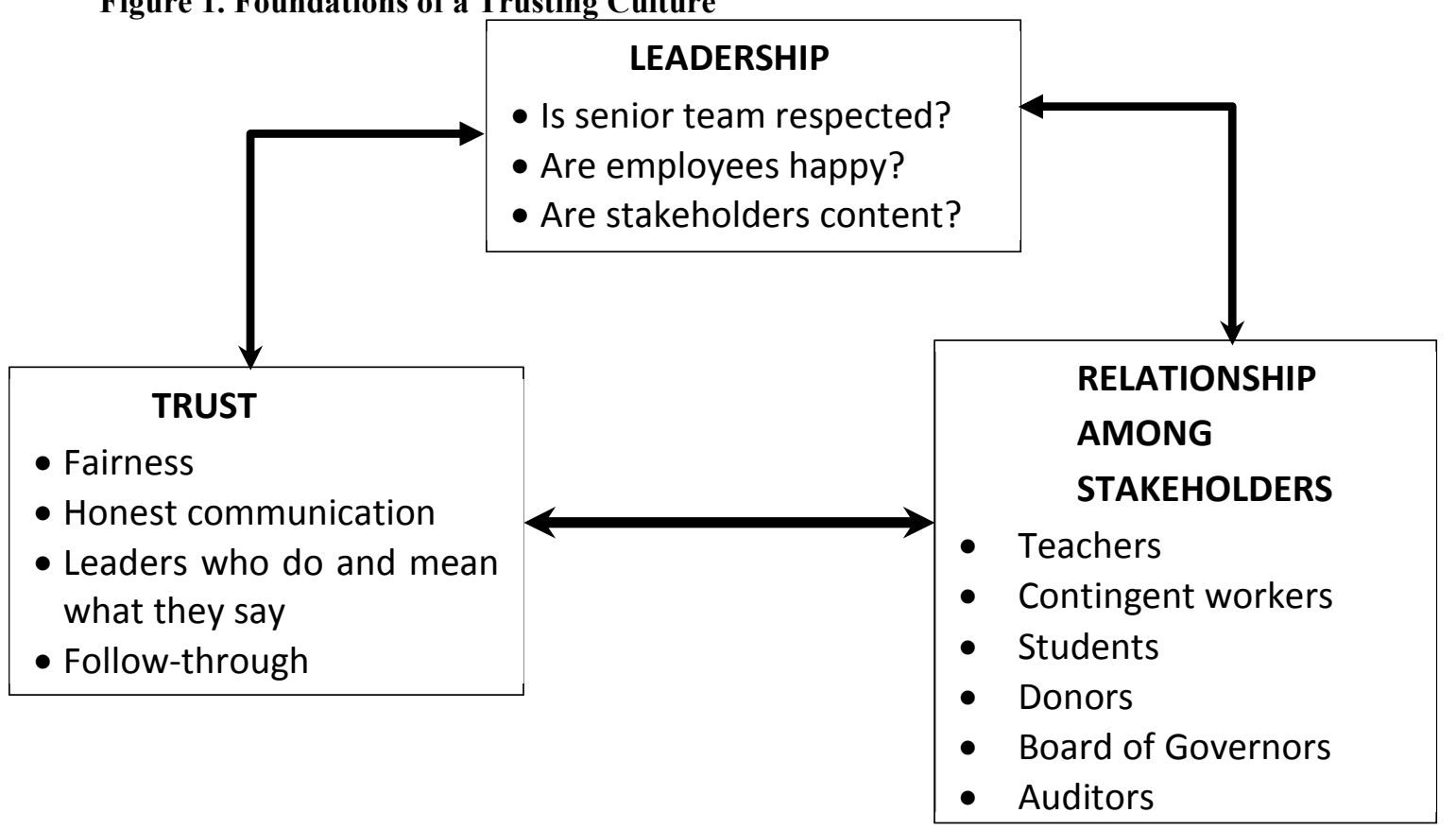

The diagram in figure 1 shows that trust is a soft skill that must be nurtured and cultivated by leaders in the school setting as well. School leaders are not only expected to exhibit their character and competence when leading others but also demonstrate integrity, motivate people and help them to plan ahead. While schools have ethics and other policies in place, it is the leaders who are expected to implement them and show their character, capabilities and competencies to the followers by demonstrating trust given that an individual cannot have trust without ethics but it is easy to have ethics without trust (Lapton, 2017). Consequently, a solid decision-making leader is desirable in the school setting that is informed by both the heart which is reflected by character and the head which reflects competence. Successful education leaders therefore are expected to manage relationships with others by walking the walk and talking the talk.

The study by van Heerden et al. (2015) focused on the widening trust gap in project management and noted that bribery, poor communication and soured relationships are key among the factors that contribute to the erosion of trust in the leadership project management process.

Moreover, according to Katarina, et al. (2010) employees learn about values through watching leaders in action which implies that the more the leaders practice what they say and walk the talk, the higher level of trust and respect it generates from followers. In the school setting, this is what compels head teachers to make personal sacrifices for followers and act within the set values.

\section{Methodology}

The study population comprised all senior teachers who have served in government aided secondary schools for a period of at least 5 years and above. For convenience in obtaining the sample, government schools in the Eastern Region of Uganda were selected. Only those secondary schools that have operated for more than 3 decades were used in the study given the reputation that the society has historically attached to them.

Questionnaires were consequently administered to 169 teachers teaching in the 11-government aided secondary schools but only 113 respondents returned completed questionnaires representing a return rate of $66.8 \%$. The questionnaire data for the eleven schools were factor analyzed using principal component analysis with varimax rotation. The procedure produced four factors. For 16 items the loadings on their respective factors ranged from .656 to .875 . An item was considered to belong to a given factor when it had its highest loading on that factor compared with other factors. The four (4) factors were termed; (1) instructional material acquisition; (2) school supervision and management; (3) teaching and student assessment; and (4) building the trust culture and guidance to staff.

The reliability of the overall questionnaire was also ascertained using Cronbach's Alpha coefficient. The coefficient for this questionnaire was .0971 which demonstrated that the questionnaire was reliable for use. 


\section{4. $\quad$ Factor Analysis Results}

Factor Analysis was employed in this research to identify two or more questions that result in a set of responses that are highly correlated among the data. The use of an eigenvalue cut-off point of 1.0, as suggested by Kaiser, resulted in four factors. The factors were then rotated using varimax rotation. The results of factor analysis for the 16 items as explained in terms of factors from varimax rotation matrix can be detailed in table 2 .

\section{Table 2. Factor loadings and communality estimates for leadership effectiveness items}

\section{Factor 1: Instructional material acquisition}

No. Item

$1 \quad$ Ethically procure, store and supervise use of school supplies and equipment

Loading

Lobby for relevant library materials

.820

.776

.820

Frequently provide update on school activities to stakeholders

Organize for the provision of facilities for
Factor 2: School supervision and management

No. Item

$1 \quad$ Allocate class responsibility to specific teachers.

Loading

Make sure that ideas and experiences shared

Make sure that team approach to problem-solving is established

4 Ensure collaboration with teachers and stakeholders heightened

\section{Factor 3: Teaching and student assessment}

No. Item

1 Seek teachers' cooperation.

Loading

.782

.866

Interview teachers in order to ascertain strengths.

821

3 Prepare and avail appropriate learning materials

Factor 4: Building trust culture and guidance to staff

No. Item

$1 \quad$ Foster collegiality, trust and harmonious working relationships among staff

Loading

.752

Mediate to resolve conflicts

.661

Avoid unethical conduct on the job

.752

Act with integrity and honesty

.897

Make sure that school culture promotes trust

.866

\section{Hypothesis Testing}

The major purpose of this research was to identify the factors that determine leadership effectiveness in the secondary schools in Uganda using a sample of schools from the Eastern Region. The hypotheses were therefore tested as follows;

\section{Hypothesis I}

The first null hypothesis stated that there are no significant factors that determine leadership effectiveness in secondary schools. The Factor analysis on the determinants of leadership items do reveal that there were four factors identified as follows; (1) school material acquisition; (2) school supervision and management; (3) teaching and succession planning; and (4) building trust culture and guidance to staff. All the four factors explained a total of $89.6 \%$ of the rotation sums of squared loadings.

In order to test this hypothesis, a correlation analysis was performed using four identified variables of; (1) school material acquisition; (2) school supervision and management; (3) teaching and assessment; and (4) building trust culture and guidance to staff and the dependent variable - leadership effectiveness. The analysis in table 4 reveals that all the extracted factors have a positive and significant correlation with leadership effectiveness. There is therefore a significant and positive relationship between leadership effectiveness and (i) instructional material acquisition $\left[\mathrm{r}=.758^{* *}, \mathrm{p}<0.0001\right]$; (ii) school supervision and management $\left[\mathrm{r}=.843^{* *}, \mathrm{p}<0.0001\right]$; (iii) teaching and student assessment $\left[\mathrm{r}=.855^{* *}, \mathrm{p}<0.0001\right]$; and (iv) building trust culture and guidance to staff $\left[\mathrm{r}=.603^{* *}\right.$, $\mathrm{p}<0.0001]$. It is therefore implied here that the school leaders are effective when they perform the function of instructional material acquisition, school supervision and management, monitoring student teaching and assessment and building a culture of trust and guidance.

Table 3. Correlation matrix of the four (4) factors and leadership effectiveness

\begin{tabular}{|c|c|c|c|c|c|}
\hline & 1 & 2 & 3 & 4 & 5 \\
\hline 1. Instructional material acquisition & - & & & & \\
\hline 2. School supervision and management & $.791 * *$ & - & & & \\
\hline 3. Teaching and student assessment & $.569 * *$ & $785 * *$ & - & & \\
\hline 4. Building trust culture and guidance to staff & $.798 * *$ & $.575 * *$ & $.414 * *$ & - & \\
\hline 5. Leadership effectiveness & $.758 * *$ & $.843 * *$ & $.855 * *$ & $.603 * *$ & - \\
\hline
\end{tabular}

**. Correlation is significant at the 0.01 level (2-tailed) 


\section{Results of Descriptive statistics on leadership effectiveness}

Leadership effectiveness was measured using by the extent to which the leader exhibits behavior on the dimensions of initiating structure and consideration for subordinates as indicated in the literature review. It can therefore be deduced from table 4 that as high as $79.6 \%$ of the respondents agreed that their leaders provide support and encourage support staff with difficult tasks. Similarly, $73.5 \%$ agreed that their leaders recognize contributions and accomplishments while $78.8 \%$ rated the leader good in providing coaching and mentoring when appropriate. Meanwhile, $69 \%$ of the teachers agreed that their leader consults with people on decisions affecting them. It should be noted however, that only $48.7 \%$ agreed that their leaders help resolve conflicts in a constructive way which implies that there is a widening trust gap in this area. Further analysis revealed that $62.8 \%$ of the respondents agreed that their leaders monitor the external environment to detect threats and opportunities, while only $59.3 \%$ viewed their leaders as individuals who can encourage and facilitate innovation in the school setting. In terms of experiment with new approaches for achieving objectives, $68.1 \%$ agreed with the statement while $61.1 \%$ rated their leaders to have influence from outside to support change. It is noted that $75.2 \%$ agreed that their leaders set specific goals and standards for task performance, $77 \%$ that their leaders direct and coordinate work activities, and $85 \%$ that they monitor operations and performance which implies that these are three key areas to which school head teachers consistently focus. They are focused on task performance in terms of teaching and assessment and less on conflict resolution hence widening the trust gap as analyzed in the subsequent section.

Table 4. Summary response for descriptive statistics on leadership effectiveness

\begin{tabular}{|c|c|c|c|c|}
\hline No. & The leader... & SA \& A & $\mathbf{N}$ & SD \& D \\
\hline 1. & Provides support and encouragement to staff with a difficult task & $79.6 \%$ & $6.2 \%$ & $14.2 \%$ \\
\hline 2. & Recognizes contributions and accomplishments & $73.5 \%$ & $8.0 \%$ & $18.6 \%$ \\
\hline 3. & Provides coaching and mentoring when appropriate & $78.8 \%$ & $9.7 \%$ & $11.5 \%$ \\
\hline 4. & Consults with people on decisions affecting them & $69.0 \%$ & $4.4 \%$ & $26.5 \%$ \\
\hline 5. & Helps resolve conflicts in a constructive way & $48.7 \%$ & $27.4 \%$ & $23.9 \%$ \\
\hline 6. & Monitors the external environment to detect threats and opportunities & $62.8 \%$ & $15.9 \%$ & $21.2 \%$ \\
\hline 7. & Encourages and facilitate innovation in the organization & $59.3 \%$ & $2.7 \%$ & $38.1 \%$ \\
\hline 8. & Experiments with new approaches for achieving objectives & $68.1 \%$ & $7.1 \%$ & $24.8 \%$ \\
\hline 9. & Influences outsides to support change & $61.1 \%$ & $16.8 \%$ & $22.1 \%$ \\
\hline 10. & Set specific goals and standards for task performance & $75.2 \%$ & 13.3 & $11.5 \%$ \\
\hline 11. & Direct and coordinate work activities & $77.0 \%$ & $10.6 \%$ & $12.4 \%$ \\
\hline 12. & Monitor operations and performance & $85.0 \%$ & $5.3 \%$ & $9.7 \%$ \\
\hline
\end{tabular}

Hypothesis 2

The second null hypothesis stated that the four (4) factors have no effect on leadership effectiveness. In order to test the above hypothesis, a regression analysis was performed using instructional material acquisition, school supervision and management, teaching and student assessment as well as building trust culture and guidance to staff which were the generated factors from factor analysis as independent variables. Leadership effectiveness was therefore used as the dependent variable. Thus, the regression model was hypothesized as follows;

$\mathrm{L} . \mathrm{E}=\beta_{0}+\mathrm{B}_{1} \mathrm{IMA}+\beta_{2} \mathrm{SM}+\beta_{3} \mathrm{TSA}+\beta_{4} \mathrm{BTC}+\varepsilon$

Where:

$\begin{array}{lll}\text { L.E } & = & \text { Leadership effectiveness } \\ \beta_{0} \beta_{1} \beta_{2} \beta_{3} \beta_{4} & = & \text { Constants in the model } \\ \text { IMA } & = & \text { Instructional material acquisition } \\ \text { SM } & = & \text { School supervision and management } \\ \text { TSA } & = & \text { Teaching and student assessment } \\ \text { BTC } & = & \text { Building trust culture and guidance to staff }\end{array}$

The analysis in table 5 reveals that among the four (4) extracted factors, only three (3) determine leadership effectiveness in the school setting and therefore the null hypothesis is rejected for the three (3) factors and accepted for the last factor which was building trust culture and guidance to staff. Put another way, leadership effectiveness in the school setting is directly influenced by three (3) factors which are; (1) instructional material acquisition [ $\beta$ $=.246, \mathrm{t}=2.902, \mathrm{p}<0.004]$, school supervision and management $[\beta=.175, \mathrm{t}=2.111, \mathrm{p}<0.037]$, and teaching and student assessment $[\beta=.544, \mathrm{t}=8.872, \mathrm{p}<0.0001]$. Therefore, leadership effectiveness is determined by the head teacher's ability to acquire of instructional materials, supervise and manage the school, and ensure that there is regular teaching and student assessment. The major finding here is that head teachers have not significantly built the trust culture and career guidance to staff which has been found insignificant with $[\beta=.081, t=1.281, p<$ 0.203]. Secondary school head teachers therefore are preoccupied with aspects concerned with teaching and learning which has been termed as initiating structure by earlier researchers. They might have given less attention to building the trust culture and solving conflicts amongst staff hence the widening trust gap at present. The model also reveals an $\mathrm{R}^{2}$ of 0.842 implying that the three factors contribute $84.2 \%$ to leadership effectiveness and the rest 
of the contribution may perhaps be from other factors such as salary and other non-monetary rewards including housing and healthcare benefits that have not been part of the investigation in this study. The Anova in table 6 also supports the general finding that there is strong main significant effect of the four (4) factors on leadership effectiveness [F $=146.840, \mathrm{p}<0.0001]$.

Table 5. Results of the regression of the four (4) factors against leadership effectiveness as a dependent variable

Variable
Intercept
Instructional material acquisition
School supervision and management
Teaching and student assessment
Building trust culture and guidance to staff
Model contribution

$\begin{array}{cc}\text { Predicted sign } & \boldsymbol{\beta} \\ +- & .329 \\ + & .246 \\ + & .175 \\ + & .544 \\ + & .081 \\ + & \mathrm{R}^{2}\end{array}$

t - value
5.478
2.902
2.111
8.872
1.281
0.842

p - value
.000
.004
.037
.000
.203

Table 6. Anova results indicating the main effect of the four (4) factors against leadership effectiveness

\begin{tabular}{lcrrrr}
\multicolumn{1}{c}{$\begin{array}{c}\text { Model } \\
\text { Regression }\end{array}$} & Sum of Squares & df & Mean Square & F & Sig. \\
Residual & 10.957 & 4 & 2.739 & 146.840 & $.000^{\mathrm{b}}$ \\
Total & 2.015 & 108 & 0.19 & & \\
\end{tabular}

a. Predictors: (Constant), Instructional material acquisition, school supervision and management, teaching and student assessment, building trust culture and guidance to staff

b. Dependent Variable: Leadership Effectiveness

\section{Discussion}

The study here documents four (4) determinant factors in the effective leadership of secondary schools in Uganda. However, head teachers investigated significantly focus on three (3) common aspects that are vital to school effectiveness which are; (1) instructional material acquisition; (2) school supervision and management; and (3) teaching and student assessment. They are not significantly concerned with one (1) aspect which is building trust culture and guidance to staff. In other words, it is teaching students and assessment aspects that they focus on without giving detailed attention to building a culture of trust and develop the propensity of staff to look at the school as a vehicle for their future career. Moreover, the study by Morrison (2013) clearly provides a set of physiognomies shared by successful school leaders that focus not only on improving teaching and learning but also promoting effective partnership with parents, businesses and the community to support student learning and progress.

The study also provides empirical support to others such as Tschannen-Moran (2014) who noted that school leaders at all levels must model and maintain trusting relationships with the different stakeholders so as to develop the conditions where staff can be vulnerable with one. Hallam et al. (2012) noted that teachers need trust not only to cope with the stress of the ever-changing demands of accountability and expectations placed on them but also the need to share control and decision making that are key aspects in increasing trust. The major implication of this research is that being inconsistent, lying, not leading by example, poor communication are aspects most likely to close the trust gap, among others (Lewicki, et al. 2006). They too outline the elements necessary to strengthen another's trust and decision making, concern for others and proximity have been shown to be the tenets of building trust over time.

\section{Conclusion}

In conclusion, the empirical study here documents key determinants of an effective head teacher as one who not only ensures instructional material requisition, school supervision and management but above all, one who ensures regular teaching and student assessment. The major finding however is that head teachers as leaders are not at present concerned with building the trust culture which is key in managing other functions as well as providing guidance to teachers which was insignificant to leadership effectiveness although it correlates significantly with all the other factors. Therefore, while the head teachers are effective in areas that focus on teaching and resource support as documented here, they are challenged to ensure that the trust culture is integrated in the system and this can be done by ensuring that there are trust building forums, conflict resolution engagements and investment in activities in which a strong bond of cooperation and collaboration is gained. Put another way, head teachers can positively contribute to school effectiveness when they are prepared and able to use extensive leadership knowledge with ethics and skills to solve complex school-based problems and with a working relationship with stakeholders including the board of governors, staff, parents, students, and the community. Only when there is integrity and a culture of trust can the performance of schools and their survival be guaranteed beyond those who are leading and managing them now. 


\section{NOTES}

*Corresponding Author: Professor Kaziba Abdul Mpaata currently works as Vice Rector, Finance and

Administration and Professor in the Faculty of Management Studies, Islamic University in Uganda;

\section{References}

Ampurire, P. (2018). UCE Results Released, Eastern Uganda Registers Highest Failures. Soft Power News.

Anthony, S.B., and Schneider, B. (2003). Trust in Schools: A Core Resource for School Reform. Educational Leadership, 60 (6), 40 - 45.

Block, L. and Manning, L. (2007). A systemic approach to developing frontline leaders in healthcare", Leadership in Health Services. 20 (2), 85 - 96.

Duignan, P. (2006). Educational Leadership: Key Challenges and Ethical Tensions. Cambridge University Press, Australia.

Fleenor, J.W., and Bryant, C. (2002). Leadership Effectiveness and Organizational Culture: An Exploratory Study. Meeting of the Society for Industrial and Organizational Psychology, Toronto.

Hallam, P.R., Chou, P.N., Hite, J.M., and Hite, S.J. (2012). Two contrasting models for mentoring as they affect retention of beginning teachers", NASSP Bulletin, 96 (3), 243-278.

Hoy, W.K., and Tschannen-Moran, M. (2003). The conceptualization and measurement of faculty trust in schools: The omnibus T-Scale", in Hoy, W.K. and Miskel, C.G. (Ed.), Studies in leading and organizing schools, CT: Information Age Publishing, Greenwich, pp. 181 - 208.

Inspectorate of Government (2014). Report to Parliament, January - June 2014. Retrieved from https://www.igg.go.ug/static/files/publications.

Katarina, K.M., Bogdan, L., and Tekavčič, M. (2010). Ethical Leadership. International Journal of Management \& Information Systems, 14 (5), $31-42$.

Laila, A. (2015). The effective school: The role of the leaders in school effectiveness. Educational Research and Reviews, 10(6), 695 - 721 .

Lapton, J. (2017). The Trust Gap in Organizations. Available at https://sfmagazine.com/post-entry/december2017-the-trust-gap-in-organizations/ (accessed 4 February 2020).

Lewicki, R.J., Tomlinson, E., and Gillespie, N. (2006). Models of interpersonal trust development: Theoretical approaches, empirical evidence, and future directions. Journal of Management, 32 (6), 991-1022.

Ministry of Education, Science, Technology and Sports (2015). A report on the USE/UPPET and UPOLET National Headcount June 2015. Education Planning and Policy Department

Morrison, N. (2013). The Eight Characteristics of Effective School Leaders. Forbes.

Mpaata, K.A. and Mpaata, Z. (2019). The Leadership Role of Secondary School Head Teachers in Delivering Integrative Quality Education in Uganda. International Journal of Educational Leadership and Management, 7(2), 203-230.

Mpaata, K.A. and Mpaata, Z. (2018). The Secondary School Head Teacher's Leadership Role in Educational Policy Implementation in Uganda. Journal of Education and Practice, 9 (17), 1 - 9.

Mpaata, K.A., Lubogoyi, B., and Okiria, J.C. (2017). The Supervisory Role of Head Teachers' and the Delivery of Primary Education in the Rural Districts of Uganda. International Journal of Science and Research, 6 (4), $458-462$.

Mpaata, K.A. (2007). The Yawning University Leadership Gap and the Quest for Quality Management in Higher Education. Nkumba Business Journal, 7 (1), 7 - 29.

Nigel, M. (2003). Effective Educational Leadership. Sage Publication, New Delhi, India.

Olatunji, A., Ojelabi, A., Isiaq, A.A., Moshood, I., and Ewaoda, A.S. (2017). Leadership training and delivery prospects of team leaders in Communication Network Support Services Limited, Ilorin. Africa's Public Service Delivery and Performance Review, 5 (1).

The Wallace Foundation. (2012). The school principal as leader: Guiding schools to better teaching and learning. New York.

Tschannen-Moran, M. (2014). Trust matters: Leadership for successful schools. $2^{\text {nd }}$ edition. Jossey-Bass, San Francisco.

Van Heerden, F.J., Steyn, J.W., and van der Walt, D. (2015). Programme management for owner teams: a practical guide to what you need to know. OTC Publications, Vaalpark, RSA.

Van Maele, D., and Van Houtte, M. (2009). Faculty trust and organizational school characteristics: An exploration across secondary schools in Flanders. Educational Administration Quarterly, 4 (4), 556-589.

Yukl, G. (2006). Leadership in organizations. Prentice Hall, Upper Saddle River, New Jersey. 